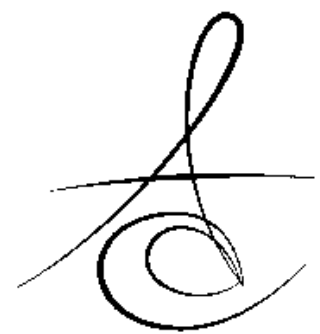

\title{
YAŞ VE CİNSİYETE GÖRE MAKSİLLER SANTRAL DİŞ RENGİ DAĞILIMININ SPEKTROFOTOMETRE İLE ÖLÇÜLMESİ
}

\author{
EVALUATION OF THE MAXILLARY CENTRAL INCISOR TOOTH COLOR \\ DISTRIBUTION ACCORDING TO AGE AND GENDER WITH \\ SPECTROPHOTOMETER
}

\author{
Dr. Öğr. Üyesi Tahir KARAMAN* \\ Dr. Öğr. Üyesi Eyyüp ALTINTAŞ* \\ Dr. Öğr. Üyesi Bekir EŞER* \\ Dr. Öğr. Üyesi Tuba TALO YILDIRIM** \\ Dr. Öğr. Üyesi Alihan BOzoĞLAN**
}

Makale Kodu/Article code: 3008

Makale Gönderilme tarihi; 31.06.2016

Kabul Tarihi: 29.12.2016

\section{Öz}

Amaç: Maksiller santral dişin renk dağılımının belirlenmesi ve yaş ile cinsiyetin diş rengi dağılımına etkisinin incelenmesi hedeflenmiştir.

Gereç ve Yöntem: Çalışmamızda yaşları 15 ile 76 arasında (yaş ortalaması 32) olan 345 gönüllü birey yer almaktadır. Gönüllülerin 183' ü erkek (\%53), 162'si kadındır (\%47). Çalışmada yer alan hastaların sağ maksiller santral diş rengi ölçümleri Vita EasyShade V spektrofotometre cihazı ile gerçekleştirilmiştir. Cihazın ucu sağ maksiller santral dişlerin labial yüzünün orta üçlüsüne dik tutularak 3 ölçüm gerçekleştirildi ve ortalaması alındı. Elde edilen veriler Vitapan Classical ve VITA Toothguide 3D-MASTER skalasına göre kaydedildi. Verilerin istatistiksel olarak analizi gerçekleştirildi.

Bulgular: Cihaz tarafından seçilen diş rengi dağılımı incelendiğinde Vitapan Classical renk skalasına göre en çok A2 $(\% 22,9)$, VITA Toothguide 3D-MASTER renk skalasına göre en çok $2 M 2 \quad(\% 21,2)$ diş rengi ölçülmüştür. Yapmış olduğumuz diş rengi ölçümü sonuçlarına göre Vita EasyShade $V$ cihazı tarafından B1, 4L2.5, 4M3 ve $5 \mathrm{M} 3$ renkleri saptanamamıştır.

Sonuç: Çalışmamızda elde edilen veriler ışığında cinsiyet ile diş rengi dağııımı arasında istatistiksel olarak anlamlı bir sonuç bulunmazken ( $p>0.05)$, yaş dağılımı ile diş rengi dağılımı arasında istatistiksel olarak anlamlı bir sonuç bulundu $(p<0.05)$.

Anahtar Kelimeler: Diş rengi, spektrofotometre, diş rengi skalaları

\section{ABSTRACT}

Aim: The purpose of this study was to investigate the determination of the maxillary central incisor color distribution and the effect of age and gender on the tooth color distribution.

Material and Methods: This study was performed on 345 volunteers varying ages between 15 and 76 (mean age 32). In the study 183 cases were male (53\%), 162 cases were female (47\%). The color of 345 volunteers' right maxillary central incisors were measured with Vita EasyShade V spectrophotometer. The tip of device was held perpendicular to middle third of the right maxillary central incisors' labial surface. Teeth were evaluated by means of three measurement of the spectrophotometer. The obtained data were recorded according to Vitapan Classical and VITA Toothguide 3D-MASTER scale. The data were analyzed statistically.

Results: The highest value was A2 (22,9\%) for Vitapan Classical scale and 2M2 (21,2\%) for 3D-MASTER scale. $B 1,4 L 2.5,4 M 3$ and $5 \mathrm{M} 3$ colors could not be determined with respect to the Vita Easyshade $\mathrm{V}$ device measurement results.

Conclusion: In this study, there was a significant difference between age and tooth color distribution $(p<0.05)$. On the other hand, no significant difference was found between gender and tooth color distribution ( $p>0.05)$

Keywords: Tooth color, spectrophotometer, dental shade guides

\footnotetext{
*Fırat Üniversitesi Diş Hekimliği Fakültesi, Protetik Diş Tedavisi A.D. Elazığ.

${ }^{* *}$ Fırat Üniversitesi Diş Hekimliği Fakültesi, Periodontoloji A.D. Elazığ.
} 


\section{GİRIŞ}

Doğal dişlerin optik özellikleri, ışık geçirgenlikleri ve yüzey özellikleri protetik restorasyonun doğal diş renginde görünmesini zorlaştırmakta ve restorasyonun estetik başarısını olumsuz etkilemektedir. Estetik restorasyonların renk seçiminde birtakım kritik faktörler rol oynamaktadır. Kişinin renk algısı, ortamda bulunan ışık kaynakları, diş ve kullanılacak materyalin yapısal ve yüzey özellikleri gibi faktörler renk seçimini etkilemektedir. ${ }^{1}$

Diş rengi seçiminde yaygın olarak konvansiyonel ve dijital yöntemler kullanılmaktadır. ${ }^{2}$ Konvansiyonel renk seçimi diş hekimliğinde en çok kullanılan yöntemdir. ${ }^{3}$ Bu yöntemde diş rengi ölçümü diş skalaları yardımıyla gerçekleştirilmektedir. Bu yöntemin uygulanması esnasında diş ve skala aynı ortamda ve ışık kaynağı altında subjektif olarak karşılaştırılarak diş rengi tespiti yapılmaktadır. Bu yöntemde ortamdaki ışık kaynağı ve subjektif özellikler (yaş, cinsiyet, tecrübe, renk körlüğü, göz yorulması vb. gibi etkenler) renk seçiminde farklı sonuçlar ortaya çıkarabilmektedir. ${ }^{4-6}$ Vitapan Classic (Vita Zahnfabrik, Bad Sackingen, Germany) ve Vita 3D Master (Vita Zahnfabrik, Bad Sackingen, Germany) renk seçiminde en sık kullanılan skalalardır ve bu skalalar ile kabul edilebilir renk seçimleri gerçekleştirilmektedir. ${ }^{7}$

Renk belirlenmesi ile ilgili yapılan araştırmalarda Munsell ve CIE renk sistemleri kullanılmaktadır. Munsel renk sisteminde renk tonu (Hue), renk değeri (Value) ve renk yoğunluğu (Chroma) rengi belirlemektedir. Hue mavi, sarı ve kırmızı rengi tanımlayan ve bir renk grubunu diğer renk grubundan ayıran özelliktir. Value parlaklık miktarı olup, cisim tarafından yansıtılan ışık miktarıdır. Düşük value değeri koyu renkleri belirtirken yüksek value değeri daha açık renkleri ifade eder. Düşük value değerleri dişi non-vital olarak gri renkte gösterir. Chroma ise rengin yoğunluğunu göstermektedir. ${ }^{8,9}$

Çalışmamızda sağ maksiller santral diş rengi dağılımının spektrofotometre cihazı ile ölçülerek diş rengi dağılımının belirlenmesi ve bu diş rengi dağılımına yaş ve cinsiyetin etkilerinin incelenmesi amaçlanmıştır. Araştırmamızda yaş ve cinsiyetin diş rengi dağııımını etkilediği yargısı hipotez olarak belirlenmiştir.

\section{GEREÇ VE YÖNTEM}

Çalışmamızda Elazığ Ağız ve Diş Sağlığı Merkezine başvuran yaşları 15 ile 76 arasında (yaş ortalaması 32) olan, 183 erkek (\%53) ve 162 kadın (\%47) olmak üzere toplam 345 gönüllü bireyin sağ maksiller santral diş rengi ölçümü gerçekleştirildi. Diş rengi ölçümü ile ilgili Fırat Üniversitesi Girişimsel Olmayan İşlemler Etik Kurulu Başkanlığı (20/06/ 2016150762) ve çalışmanın gerçekleştirildiği Elazığ Ağız ve Diş Sağlığı Merkezi kurum onayı alındı.

Diş rengi ölçümleri standardizasyonun sağlanması amacıyla aynı klinik ve diş ünitesinde, doğal gün ışığında ve 10-12 saatleri arasında gerçekleştirildi. Diş rengi ölçümü esnasında, hastaların yüzünde ve elbisesinde parlak renkler hasta önlüğü ile örtüldü. Diş rengi ölçümü öncesi Vita EasyShade V (Vita Zahnfabrik, Bad Sackingen, Germany) cihazına enfeksiyon kontrol kalkanı (VITA EasyShade Infection Control Shield, Vita Zahnfabrik, Bad Sackingen, Germany) takıldı ve üretici talimatlarına göre her diş rengi ölçümü öncesi cihazın kalibrasyonu yapıldı.

Sağ maksiller santral dişlerinde restorasyon, çürük, endodontik tedavi, ortodontik tedavi ve bleaching işlemi uygulanmış hastalar çalışmaya dahil edilmedi. Diş üzerinde ölçüm öncesi plak indeksi kontrolü yapıldı ve plak indeksi 0 olan diş yüzeyinde ölçümler gerçekleştirildi. Diş rengi ölçümü öncesi diş yüzeyindeki tükrüğü uzaklaştırmak için, dişler hava su spreyi ile yıkandı ve pamuk tampon ile silindi. Cihazın ucu sağ maksiller santral dişlerin labial yüzünün orta üçlüsüne dik tutularak, 'tek ölçüm' modunda ardı ardına 3 ölçüm gerçekleştirildi. Elde edilen veriler Vita EasyShade V cihazında hazır bulunan program sayesinde Vitapan Classical ve VITA Toothguide 3D-MASTER skalasına göre kaydedildi. Vita EasyShade V cihazı ile renk ölçümü gerçekleştirilirken, arka zemin yansımalarının engellenmesi için gri arka plan kullanıldı (Resim 1).

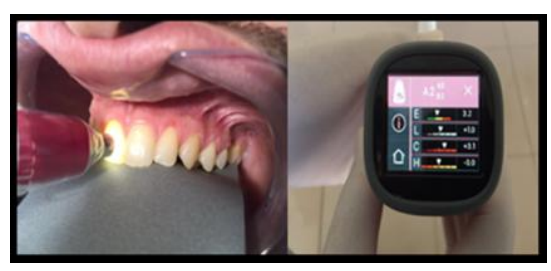

Resim 1. Vita EasyShade cihazı ile diş rengi ölçümlerinin gerçekleştirilmesi 
Tüm istatistiksel analizler SPSS 15.0 (SPSS Inc., Chicago, IL) veri analiz programı ile gerçekleştirildi. Elde edilen verilere göre cinsiyet ve yaş dağılımının diş rengi ile ilişkisinin belirlenmesinde ki-kare testi kullanıldı.

\section{BULGULAR}

Çalışmamızda diş rengi ölçülen 345 bireyin $\% 30,7$ 'si 15-24 yaş grubunda (106), \% 31,3'ü 25-34 yaş grubunda (108), \%24,4'ü 35-44 yaş grubunda (84) ve $\% 13,6$ 's Ise 45 ve üzeri yaş grubunda (47) bulunmaktadır.

Tüm bireylerin cinsiyet ve yaş ayrımı yapılmadan Vita EasyShade V cihazı tarafından seçilen Vitapan Classical renk dağılımı Şekil 1'de gösterilmiştir.

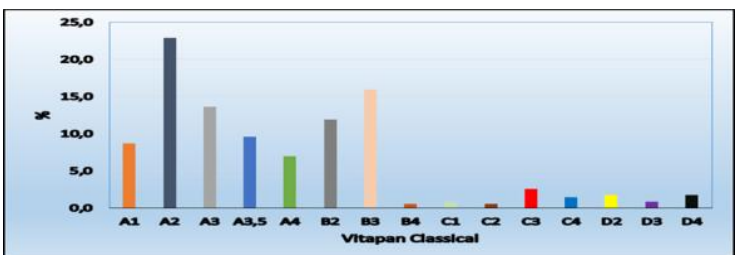

Şekil 1. Sağ maksiller santral dişlerin Vitapan Classical renk skalasına göre renk dağılımı

Cihaz tarafından seçilen diş rengi dağılımı incelendiğinde Vitapan Classical renk skalasına göre en çok A2 $(\% 22,9)$ diş rengi, en az B4 $(\% 0,6)$ ve C2 $(\% 0,6)$ renkleri ölçülmüştür. Yapılan diş rengi ölçümü sonuçlarına göre Vita EasyShade V cihazı tarafından B1 diş rengi saptanamamıştır.

Cinsiyet ve yaş ayrımı yapılmaksızın Vita EasyShade V cihazı ile diş renk ölçümü gerçekleştirilen bireylerin VITA Toothguide 3D-MASTER skalasına göre renk dağılımı Şekil 2'de gösterilmiştir.

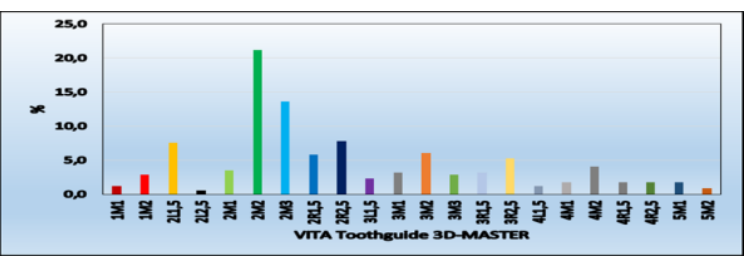

Şekil 2. Sağ maksiller santral dişlerin VITA Toothguide 3DMASTER renk skalasına göre renk dağıımı

Cihaz tarafından seçilen diş rengi dağılımı incelendiğinde VITA Toothguide 3D-MASTER renk skalasına göre en çok $2 \mathrm{M} 2(\% 21,2)$ diş rengi, en az 2L2,5 $(\% 0,6)$ rengi ölçülmüştür. Yapmış olduğumuz diş rengi ölçümü sonuçlarına göre Vita EasyShade V cihazı tarafından $4 \mathrm{~L} 2.5,4 \mathrm{M} 3$ ve $5 \mathrm{M} 3$ renkleri saptanamamıştır.

Cinsiyete göre diş renginin Vitapan Classical skalasına göre dağııı şekil 3'de gösterilmiştir.

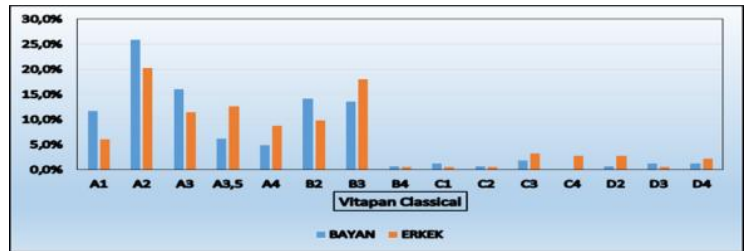

Şekil 3. Cinsiyete göre sağ maksiller santral dişlerin Vitapan Classical renk skalasına göre renk dağııımı

Cihaz tarafından seçilen diş rengi dağılımı Vitapan Classical renk skalası ve cinsiyete göre değerlendirildiğinde en çok A2 diş rengi dağılımının olduğu belirlenmiştir. Bu oran bayanlarda $\% 25,9$, erkeklerde ise \%20,2 olarak bulunmuştur. Ayrıca Bayanlarda C4 ve B1, Erkeklerde ise B1 renkleri saptanamamıştır. Cinsiyet ile Vitapan Classical renk skalasına göre diş rengi dağılımı arasında istatistiksel olarak anlamlı bir sonuç bulunamadı ( $p>0.05)$.

Cinsiyete göre diş renginin VITA Toothguide 3D-MASTER skalasına göre dağılımı Şekil 4'de gösterilmiştir.

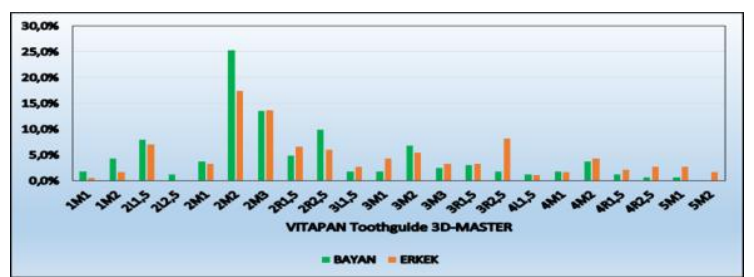

Şekil 4. Cinsiyete göre sağ maksiller santral dişlerin VITA Toothguide 3D-MASTER skalasına göre renk dağılımı

Cinsiyet ile VITA Toothguide 3D-MASTER skalası diş renk dağılımı arasında istatistiksel olarak anlamlı bir sonuç bulunamadı ( $p>0.05)$. Cihaz tarafından seçilen diş rengi dağılımı VITA Toothguide 3D-MASTER skalası ve cinsiyete göre incelendiğinde en çok $2 \mathrm{M} 2$ diş rengi dağılımının olduğu belirlenmiştir. Bu oran bayanlarda \%25,3, erkeklerde ise \%17,5 bulunmuştur. Ayrica Bayanlarda 5M2 ve 5M3, Erkeklerde ise 2L2,5 ve $5 \mathrm{M} 3$ renkleri saptanamamıştır.

Yaş dağılımına göre sağ maksiller santral dişlerin Vitapan Classical renk skalasına göre renk dağılımı Şekil 5'de gösterilmektedir.

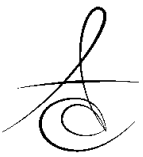




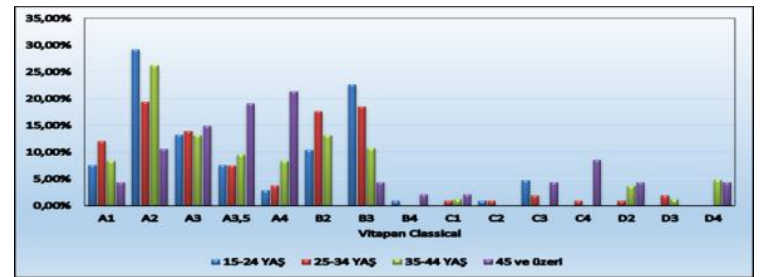

Şekil 5. Yaş dağılımına göre sağ maksiller santral dişlerin Vitapan Classical renk skalasına göre renk dağılımı

Yaş dağılımı ile Vitapan Classical renk skalasına göre diş rengi dağılımı arasındaki ilişki istatistiksel olarak anlamlı bulundu $(\mathrm{p}<0.05)$. Cihaz tarafından seçilen diş rengi Vitapan Classical renk skalası ve 1524 yaş arası dağılımına göre incelendiğinde en çok A2 diş rengi dağılımının olduğu ve bu oranın \% 29,2 olduğu belirlenmiştir. Ayrıca bu yaş dağılımında B1, C1, C4, D2, D3, D4 renkleri saptanamamıştır. 25-34 yaş arası dağılımına göre en çok $A 2(\% 19,4)$ diş rengi dağılımının olduğu ve bu yaş aralığında B1, B4 ve D4 diş rengi saptanamamıştır. 35-44 yaş arası dağıııına göre en çok $A 2(\% 26,2)$ diş rengi dağılımının olduğu ve bu yaş aralığında B1, B4, C2, C3 ve C4 diş rengi saptanamamıştır. 45 ve üzeri yaş dağılımına göre en çok A4 $(\% 21,3)$ diş rengi dağılımının olduğu ve bu yaş aralığında B1, B2, C2 ve D3 diş rengi saptanamamıştır.

Yaş dağılımına göre sağ maksiller santral dişlerin VITA Toothguide 3D-MASTER renk skalasına göre renk dağılımı Şekil 6'da gösterilmektedir.



Şekil 6. Yaş dağılımına göre sağ maksiller santral dişlerin VITA Toothguide 3D-MASTER renk skalasına göre renk dağılımı

Yaş dağılımı ile VITA Toothguide 3D-MASTER renk skalası diş rengi dağılımı arasındaki ilişki istatistiksel olarak anlamlı bulundu $(p<0.05)$. Cihaz tarafından seçilen diş rengi VITA Toothguide 3D-MASTER renk skalası ve 15-24 yaş arası dağılımına göre incelendiğinde en çok $2 \mathrm{M} 2$ diş rengi dağılımının olduğu ve bu oranın \% 21,7 olduğu belirlenmiştir. Ayrıca bu yaş dağlımında ise 1M1, 2L2.5, 3L1.5, 4L2.5, 4M3, 5M1, 5M2 ve $5 \mathrm{M} 3$ renkleri saptanamamıştır. $25-34$ yaş arası dağılımına göre en çok 2M2 $(\% 20,4)$ diş rengi dağıımının olduğu ve bu yaş aralığında ise 4L1.5, 4L2.5, 4R1.5, 4R2.5, 4M3, 5M2 ve $5 \mathrm{M} 3$ diş rengi saptanamamıştır. 35-44 yaş arası dağılımına göre en çok $2 \mathrm{M} 2(\% 28,6)$ diş rengi dağılımının olduğu ve bu yaş aralığında ise 1M2, 2L2.5, 4L1.5, 4L2.5, 4M2, 4M3, 5M2 ve 5M3 diş rengi saptanamamıştır. 45 ve üzeri yaş dağılımına göre en çok 4M2 $(\% 17,0)$ diş rengi dağııımının olduğu ve bu yaş aralığında ise $1 \mathrm{M} 1,2 \mathrm{~L} 2.5,2 \mathrm{M} 3,3 \mathrm{R} 2.5,4 \mathrm{~L} 1.5$, $4 \mathrm{M} 3$ ve $5 \mathrm{M} 3$ diş rengi saptanamamıştır.

\section{TARTIŞMA}

Bulgular neticesinde hipotezimiz kısmen reddedilmiş olup, diş rengi dağılımının cinsiyete göre etkilenmediği bulundu. Yaş dağılımı ile diş rengi dağıımı arasında ise istatistiksel olarak anlamlı bir sonuç bulunmuş ve hipotezimiz kısmi olarak desteklenmiştir.

Dental estetiğin son yıllarda önem kazanmasıyla birlikte diş hekimlerinin renk seçimi ve uygun restorasyon yapımına verdikleri önem artmıştır. ${ }^{10}$ Dişlerin uniform bir rengi olmayıp, rengin oluşmasında ton (Hue), yoğunluk(Chroma) ve parlaklığın(Value) oranı rengi belirlemektedir. ${ }^{8,9}$ Komşu dişler ile yapılan sabit protetik restorasyonların estetik başarısında dişin doğal formunun sağlanmasının yanında, renk ve yüzey formunun uyumlu olması gerekir. ${ }^{4,8}$

Diş renginin ölçülmesi amacıyla araştırmacılar tarafından yapılan çalışmalarda, cinsiyet ile diş rengi arasında anlamlı bir sonuç bulunmadığı bildirilmiştir. ${ }^{11-}$ 14 Tunçdemir ve ark. tarafından yapılan araştırmada, maksiler kanin ve santral dişler üzerinde spektrofotometre cihazı ile ölçümler gerçekleştirilmiş ve cinsiyete göre renk farklılığı istatistiksel olarak anlamlı bulunmamıştır. ${ }^{13}$ Cinsiyetin ve yaşın diş rengini etkilemediğini belirten çalışmaların yanında bunun tersini savunan ve cinsiyet ile diş rengi arasında anlamlı bir sonuç bulunan çalışmalarda mevcuttur. ${ }^{15,16}$ Diş rengi ile yaş arasındaki ilişkinin incelendiği çalışmalarda ise santral kesici dişlerin ileri yaşlarda daha koyu, daha kırmızı ve daha sarı tonlarına sahip olduğu bildirilmiştir. ${ }^{15,17}$ Çalışmamızda cinsiyet ile diş rengi dağıııı arasında istatistiksel olarak anlamlı bir sonuç bulunmazken ( $p>0.05)$, yaş dağılımı ile diş rengi dağııımı arasında istatistiksel olarak anlamlı bir sonuç bulundu $(p<0.05)$.

Diş renginin ölçülmesi ve dağılımı ile ilgili birçok çalışma gerçekleştirilmiştir. Yapılan çalışmalarda diş renginin belirlenmesinde konvansiyonel ve dijital yön-

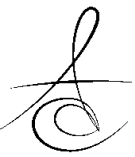


temler kullanılmıştır. ${ }^{2-4,6,18,19}$ Dijital aygıtlar renk belirlenmesinde standart bir ölçüm sağladıklarından dolayı konvansiyonel yöntemlere göre daha güvenilirdirler. ${ }^{2,13,20}$ Konvansiyonel ve dijital diş rengi ölçüm yöntemlerinin birbiriyle kıyaslandığı çalışmalarda renk ölçüm cihazlarının daha iyi sonuçlar verdiği bildirilmiştir. 2,20-22 Chen ve ark. konvansiyonel yöntem ve cihazla gerçekleştirilen ölçümlerin incelendiği derleme çalışmasında, spektrofotometre cihazı ile gerçekleştirilen ölçümlerin daha kesin olduğunu belirtmişlerdir. ${ }^{2}$ Çalışmamızın diş rengi ölçümleri, Vita EasyShade V cihazı ile gerçekleştirildi.

Diş rengi seçimleri ile ilgili çalışmalarda, araştırmacılar tarafından çeşitli dişlerin renklerinin ölçümleri gerçekleştirilmiştir..$^{3-5,11,13}$ Dişlerin anatomik yüzeyleri ve spektrofotometre cihazınının konumlandırılması gibi faktörler diş rengi ölçümlerini etkilemektedir. ${ }^{4}$ Maksiller santral dişler daha düz bir labial yüzeye sahip olmaları ve ölçüm esnasında cihazın ve hekimin konumlama ile ilgili sıkıntı yaşamaması için tercih edildi. Standardizasyonun sağlanması amacıyla tüm hastaların maksiller sağ santral dişleri çalışmaya dahil edildi.

Diş rengi ölçümü gerçekleştirilirken diş yüzeyleri ile ilgili ölçüm öncesi farklı işlemler gerçekleştirilmiştir. Ölçüm öncesi diş yüzeyinin polisajlanması ${ }^{23,24}$, diş fırçası ile temizlenmesi ${ }^{18,25}$ ve herhangi bir işlem yapılmayıp doğrudan ölçümün yapılması ${ }^{22,26}$ şeklinde gerçekleştirilmiştir.

Diş rengi ölçümünde arka planın seçilen diş rengine ve yapılan restorasyonlara etkilerinin incelendiği birtakım çalışmalar gerçekleştirilmiştir. Ma ve ark. tarafından yapılan araştırmada arka planın restorasyon rengini etkilemediği ${ }^{27}$, bazı çalışmalarda ise restorasyonların renginde arka planın etkili olduğu bildirilmiştir. ${ }^{24,28-30}$ Ardu ve ark. arka plan renginin diş rengi ölçümüne olan etkilerini incelemişlerdir. Yapılan çalışmada beyaz, siyah ve gri arka plan spektrofotometrik ölçümleri ile, arka plan olmadan yapılan spektrofotometrik ölçümler arasında önemli farklılıklar bulunmuştur. Ayrıca siyah ve gri arka planın renk ölçümünde ağız koşullarını daha iyi simüle ettiği bildirilmiştir. ${ }^{24}$ Çalışmamızda cihaz verilerinin arka plandan etkilenmesini elimine etme amacıyla gri arka plan kullanıldı. Bunun yanında diş rengi ölçümünde herhangi bir arka plan kullanılmadan, doğrudan ölçümler gerçekleştirilen çalışmalar da mevcuttur. ${ }^{18,22,25,31}$

Ortamdaki ışık renk sıcaklığı da seçilen diş rengini etkilemekte olup, araştırmacılar diş rengi ölçümü- nü $5500 K^{22,23}$ ile $6500 K^{18,24,32}$ arasında gerçekleştirmişlerdir. Gün ışığı ortalama sıcaklık değeri $6500 \mathrm{~K}$ olarak belirtilmiştir ve günün farklı saatleri, havadaki bulut, nem oranı ve kirlilik renk sıcaklığında değişikliklere yol açmaktadır. ${ }^{33}$

Türk toplumundaki diş renginin dağılımı ile ilgili araştırmacılar tarafından bir takım çalışmalar gerçekleştirilmiş olup, Eroğlu ve ark. tarafından yapılan maksiller santral diş rengi dağılımının araştırıldığı çalışmada en çok B2 ve B3 diş rengi tespit edilmiştir. ${ }^{34}$ Kurtulmuş-Yılmaz ve ark. tarafından yapılan genç bireylerin diş rengi dağılımını inceleyen araştırmalarında tüm bireylerin maksiler santral diş renginin en çok $A 1$ ve B2 olduğu, doğal diş renklerinin cinsiyetler arasında farklılık gösterdiği bildirilmiştir. ${ }^{35}$ Öngül ve ark.'nın yaptıkları çalışmada, Vitapan Classical skalasına göre B2, C2 ve C3 renkleri yoğun bir dağılım gösterirken, Vita 3D Master skalasına göre 2M1, $3 \mathrm{~L} 1.5$ ve 2L1,5 renkleri ağırlıklı dağıım göstermiştir. ${ }^{36}$ Araştırmamızda 15-24 ve 25-34 yaş grubundaki bireylerin maksiller sağ santral renk ölçüm sonuçlarına göre Vitapan Classical skalasında en çok A2, VITA Toothguide 3D-MASTER skalasında ise $2 \mathrm{M} 2$ diş rengi tespit edildi.

\section{SONUÇ}

Çalışmamızda, cinsiyet ile diş rengi dağılımı arasında istatistiksel olarak anlamlı bir sonuç bulunmazken ( $p>0.05)$, yaş dağılımı ile diş rengi dağılımı arasında istatistiksel olarak anlamlı bir sonuç bulundu $(p<0.05)$. Cihazın belirlediği renk dağılım grafikleri incelendiğinde Vitapan Classical diş rengi dağılımının daha çok A tonlarında(\%61,7) yoğunlaştığı görülmüştür. VITA Toothguide 3D-MASTER renk skalasına göre ise renk yoğunluğu daha çok $2 \mathrm{M}$ tonlarında saptanmıştır. Yapmış olduğumuz diş rengi ölçümü sonuçlarına göre Vitapan Classical skalasına göre B1 diş rengi, VITA Toothguide 3D-MASTER skalasına göre ise $4 \mathrm{~L} 2.5,4 \mathrm{M} 3$ ve $5 \mathrm{M} 3$ renkleri saptanamamıştır.

\section{TEŞEKKÜR}

Araştırmamızın istatistik verilerini değerlendiren Dr. Öğr. Üyesi İhsan SERHATLIOĞLU' na teşekkür ederiz.

Tahir Karaman: ORCID ID: 0000-0002-3764-637X Eyyüp Altıntaş: ORCID ID: 0000-0002-7767-9694 Bekir Eşer: ORCID ID: 0000-0002-1280-1257

Tuba Talo Yıldırım: ORCID ID: 0000-0002-7577-5703 Alihan Bozoğlan: ORCID ID: 0000-0003-3420-5816 


\section{KAYNAKLAR}

1. Vichi A, Louca C, Corciolani G, Ferrari M. Color related to ceramic and zirconia restorations: a review. Dent Mater 2011;27:97-108.

2. Chen H, Huang J, Dong X, Qian J, He J, Qu X, et al. A systematic review of visual and instrumental measurements for tooth shade matching. Quintessence Int 2012;43:649-59.

3. Hugo B, Witzel T, Klaiber B. Comparison of in vivo visual and computer-aided tooth shade determination. Clin Oral Investig 2005;9:244-50.

4. Dozić A, Kleverlaan CJ, El-Zohairy A, Feilzer AJ, Khashayar G. Performance of five commercially available tooth color-measuring devices. J Prosthodont 2007;16:93-100.

5. Hammad IA. Intrarater repeatability of shade selections with two shade guides. J Prosthet Dent 2003;89:50-3.

6. Okubo SR, Kanawati A, Richards MW, Childressd S. Evaluation of visual and instrument shade matching. J Prosthetic Dent 1998;80(6):642-48.

7. Brewer JD, Wee A, Seghi R. Advances in color matching. Dent Clin North Am 2004;48:341-58.

8. Rosentiel S, Land M, Fujimoto J. Contemporary Fixed Prosthodontics. 4th Ed. 2006;709-39

9. O'Brien WJ. Dental materials and their selection, 4th Ed. Quintessence. 2008;25-37

10. Bayındır F, Bayındır YZ. Restoratif diş hekimliğinde dişeti rengi seçimi ve dişeti skalaları. Atatürk Üniv Diş Hek Fak Derg 2010;3:38-43.

11. Al-Saleh S, Tashkandi E. Three-dimensional color Coordinates of Natural Teeth in a Sample of Young Saudis: a pilot study. Saudi Dent J 2007;19:97100.

12. Hasegawa A, Motonomi A, Ikeda I, Kawaguchi S. Color of natural tooth crown in Japanese people. Col Res Appl 2000;25:43-8.

13. Tuncdemir AR, Polat S, Ozturk C, Tuncdemir MT, Gungor AY. Color differences between maxillar and mandibular incisors. Eur J Gen Dent 2012;1:170.

14. Zhu $H$, Lei $Y$, Liao N. [Color measurements of 1,944 anterior teeth of people in southwest of China-discreption]. Zhonghua kou qiang yi xue za zhi= Zhonghua kouqiang yixue zazhi= Chinese $\mathrm{J}$ Stomatol 2001;36:285-8.

15. Gozalo-Diaz D, Johnston WM, Wee AG. Estimating the color of maxillary central incisors based on age and gender. J Prosthet Dent 2008;100:93-8.
16. Odioso L, Gibb R, Gerlach R. Impact of demographic, behavioral, and dental care utilization parameters on tooth color and personal satisfaction. Compen Contin Educ Dent (Jamesburg, NJ: 1995) Supplement 1999:S35-41; quiz S43.

17. Hasegawa A, Ikeda I, Kawaguchi S. Color and translucency of in vivo natural central incisors. The J Prosthet Dent 2000;83:418-23.

18. Pop-Ciutrila I-S, Colosi HA, Dudea D, Badea ME. Spectrophotometric color evaluation of permanent incisors, canines and molars. A cross-sectional clinical study. Clujul Medical 2015; 88: 537.

19. Lasserre J-F, Pop-Ciutrila I-S, Colosi H-A. A comparison between a new visual method of colour matching by intraoral camera and conventional visual and spectrometric methods. J Dent 2011;39:29-36.

20. Bahannan SA. Shade matching quality among dental students using visual and instrumental methods. J Dent 2014;42:48-52.

21. Kröger $E$, Matz S, Dekiff M, Tran BL, Figgener $L$, Dirksen D. In vitro comparison of instrumental and visual tooth shade determination under different illuminants. J Prosthet Dent 2015;114:848-55.

22. Pimental W, Tiossi R. Comparison between visual and instrumental methods for natural tooth shade matching. Gen Dent 2014;62:47-9.

23. AlSaleh S, Labban M, AlHariri M, Tashkandi E. Evaluation of self shade matching ability of dental students using visual and instrumental means. J Dent 2012;40:82-87.

24. Ardu S, Feilzer AJ, Devigus A, Krejci I. Quantitative clinical evaluation of esthetic properties of incisors. Dent Mater 2008;24:333-40.

25. Özat P, Tuncel I, Eroğlu E. Repeatability and reliability of human eye in visual shade selection. J Oral Rehabil 2013;40:958-64.

26. Kuzmanovic D, Lyons K. Tooth shade selection using a colorimetric instrument compared with that using a conventional shade guide. New Zealand Dent J 2009;105:131-4.

27. Ma $Y$, Zhang N, Deng X. Influence of background color on chromatic value of four all-ceramic system core materials. Zhonghua kou qiang yi xue za zhi= Zhonghua kouqiang yixue zazhi. Chinese J Stomatol 2010;45:367-9. 
28. Ritter DD, Rocha RO, Soares FZ, Lenzi TL. Do adhesive systems influence the color match of resin composites? J App Biomater Func Mater 2016;14:212-6.

29. Lee YK, Lim BS, Kim CW. Difference in the colour and colour change of dental resin composites by the background. J Oral Rehabil 2005;32:227-33.

30. Turgut S, Bagis B. Effect of resin cement and ceramic thickness on final color of laminate veneers: an in vitro study. J Prosthet Dent 2013;109:179-86.

31. Meireles SS, Demarco FF, Santos IdSd, Dumith SdC, Bona AD. Validation and reliability of visual assessment with a shade guide for tooth-color classification. Oper Dent 2008;33:121-6.

32. Al-Dosari AAF. Reliability of tooth shade perception by dental professionals and patients. Pakistan Oral \& Dental Journal 2010;30:244-9.

33. Shammas M, Alla RK. Color and shade matching in dentistry. Trends Biomater Artif Organs 2011;25:172-75.

34. Eroğlu E, Küçükeşmen HC, Uluhan B. SD Ü. Diş Hekimliği Fakültesi Protetik Diş Tedavisi Kliniğine Müracaat Eden Hastaların Diş Rengi Dağılımının Saptanması. SDÜ Tıp Fak Derg 2007;14:28-31.

35. Kurtulmuş-Yılmaz S, Şeker E, Ozan O, Meriç G, Ulusoy M. Genç Kuzey Kıbrıs Türk popülasyonunun doğal diş renginin değerlendirilmesi: pilot çalışma. Cumhuriyet Dent J 2011;14:164-74.

36. Öngül D, Çelik B, İlbey D, Şermet B. Türk toplumundaki genç bireylerde diş renk dağılımının incelenmesi. İstanbul Üniv Diş Hek Fak Derg 2013; 47:30-40.

\author{
Yazışma Adresi \\ Tahir Karaman \\ Fırat Üniversitesi \\ Diş Hekimliği Fakültesi \\ Protetik Diş Tedavisi AD. \\ Elazığ \\ Fax:+904242378986 \\ Tel: +905375679559, , \\ e-mail: tkaraman@firat.edu.tr
}

